\begin{tabular}{cc|c}
\hline Tar. Bil. Der. & Journal of Agricultural Sciences \\
& $\begin{array}{c}\text { Dergi web sayfası: } \\
\text { www.agri.ankara.edu.tr/dergi }\end{array}$ & Journal homepage: \\
& www.agri.ankara.edu.tr/journal
\end{tabular}

\title{
Measurement and Prediction of Total Friction Losses in Drip Irrigation Laterals with Cylindrical Integrated in-line Drip Emitters using CFD Analysis Method
}

\author{
Vedat DEMİR ${ }^{\mathrm{a}}$, Hüseyin YÜRDEM ${ }^{\mathrm{a}}$, Arzu YAZGI ${ }^{\mathrm{a}}$, Tuncay GÜNHAN ${ }^{\mathrm{a}}$ \\ ${ }^{a}$ Department of Agricultural Machinery and Technologies Engineering, Faculty of Agriculture, Ege University, İzmir, TURKEY
}

\section{ARTICLE INFO}

Research Article

DOI: 10.15832 /ankutbd. 433830

Corresponding Author: Vedat DEMIR, E-mail: vedat.demir@ege.edu.tr, Tel: +90 (232) 3112824

Received: 13 June 2018, Received in Revised Form: 13 August 2018, Accepted: 15 August 2018

\begin{abstract}
The objective of this study was to predict total friction losses in drip irrigation laterals with cylindrical integrated inline emitters at different spacing using Computational Fluid Dynamics (CFD) simulation method. Two types of drip irrigation laterals with different technical specifications were used in the study. In the laboratory, the total friction losses were measured in the laterals for different velocities. In CFD analysis, standard $k-\varepsilon$, RNG $k-\varepsilon$, realizable $k-\varepsilon$, Reynolds Stress (RSM) with Linear Pressure-Strain (LPS) turbulence models and standard wall function, non-equilibrium wall function, enhanced wall treatment were considered. CFD simulation results were compared with experimental total friction losses in laterals. The highest prediction was obtained by RSM turbulence model with LPS using standard wall function with the lowest values of MAPE (2.96\%) and RMSE (369 Pa).
\end{abstract}

Keywords: Drip irrigation; Pipe; Turbulence models; Computational fluid dynamics

(C) Ankara Üniversitesi Ziraat Fakültesi

\section{Introduction}

Uniform water distribution along the drip irrigation lateral lines is effected by many factors. Several of them are related to the external influences that are emitter clogging, emitter manufacturing variations, water temperature differences etc. The other important factor is friction losses along the lateral, which is related to construction and spacing of the drip emitter and pipe roughness. The pressure distribution along the lateral line changes with the friction loss and the lateral slope. These pressure changes along the lateral directly affect the flow rates of drip emitter in the lateral line. As a consequence, the water distribution uniformity in the field is negatively affected. This is especially important for full-turbulence flow and non-compensated drip emitters.

Drip irrigation laterals have multiple outlets depending on the emitter type and spacing. In general, the drip emitter flow rate and hydraulic pressure relation is characterized by following Equation (Von Bernuth \& Solomon 1986).

$q=k H^{x}$

In Equation; $q$, flow rate of drip emitter $\left(\mathrm{L} \mathrm{h}^{-1}\right) ; H$, inlet pressure of drip emitter (m); $k$, flow coefficient 
$\left(\mathrm{L} \mathrm{h}^{-1} \mathrm{~m}^{-\mathrm{x}}\right) ; x$, exponent of inlet pressure. The flow coefficient $(k)$ depends on the physical dimensions of the water passage paths in the drip emitter.

The pressure at anywhere along the lateral line, in other words the inlet pressure of the drip emitter at that point can be calculated by the following equation.

$$
H_{i}=H_{i-1}-\Delta H_{K} \pm \Delta H_{g}
$$

Where; $H_{i}, i$ th drip emitter inlet pressure at anywhere along lateral line $(\mathrm{m}) ; H_{i-1}$, previous drip emitter inlet pressure (m); $\Delta H_{K}$, friction loss between two emitters (m); $\Delta H_{g}$, pressure loss or gain due to the incline between two emitters $(\mathrm{m})$.

Therefore, all friction and local losses based on the protrusion of drip emitters in laterals have to be considered for accurate evaluation the total friction losses along the laterals.

$$
\Delta H_{K}=\Delta H_{f}+\Delta H_{k}
$$

Several studies have been carried out on total friction and local losses for different type emitters. Inner diameter of the integrated cylindrical drip emitter is usually smaller than the pipe. As a consequence, this structure causes contraction of the flow paths at the up-stream of the drip emitter and the expansion of the flow paths downstream from the drip emitters. So, all frictional losses have to be considered in lateral design (Bagarello et al 1997; Juana et al 2002; Provenzano \& Pumo 2004).

Provenzano et al (2005a) measured the total head losses for co-extruded laterals, and a new Equation was developed by considering the total local loss on account of the emitter connections. Besides these mathematical based studies, there are different approaches on determining of the head losses and required uniformity of water application. For instance, Anyoji \& Wu (1987) used statistical methods, while Kang \& Nishiyama (1996) applied finite element method in their studies. Demir et al (2007) developed mathematical model in drip laterals for in-line and on-line emitters using dimensional analysis to prediction total friction losses. Provenzano et al (2014) presented an empirical local loss prediction model for lay-flat drip laterals.

Computational Fluid Dynamics (CFD) is a method which is commonly used for the determination of the performance of product in the design, improvement of the product performance on computer and manufacturing of final product in optimal performance. Some of the advantages of using CFD are providing of minimum number of prototype production for test, decreasing of investment and time necessities. The studies conducted using CFD method in drip irrigation systems can be grouped into two main categories which are the dripper design and the lateral hydraulic. CFD was also applied in the studies related to drip irrigation system for only determining of flow characteristics on streamline and revealing of dripper design parameters (Wei et al 2006; Wang et al 2006; Zhang et al 2007).

The limited numbers of studies conducted using CFD about friction losses in drip irrigation laterals included local losses are summarized below:

Provenzano et al (2005b) and Provenzano et al (2007) evaluated the friction and local losses in laterals with pressure compensating in-line coextruded emitters by using CFD method. They used standard $k-\varepsilon$ turbulence model for CFD analysis obtained using at different Reynolds numbers and found that the differences of total friction losses obtained by experimental and CFD analysis varied between $-4.7 \%$ and $10.9 \%$. They stated that, the total friction losses in polyethylene laterals can be simulated by CFD method for low turbulence regimes very closely.

Palau-Salvador et al (2006), revealed the behavior of the flow around the protrusion of the online type dripper emitters in the lateral by means of CFD analysis that used the Reynolds Stress Model (RSM) and SIMPLE algorithm. They compared experimental and CFD analysis results of local loss data, and found the better simulation for the larger protrusion area and the turbulence. 
In the literature, there were numerous analytical and experimental studies carried out to determine the frictional losses in the laterals, accurately and easily. In recent years, researchers continue to work on this subject. In addition, limited numbers of CFD simulation based studies have been carried out on determination of friction losses. However, there is not any study on the comparison of the simulation models.

The main objective of this study was to predict the total friction losses in drip irrigation laterals with cylindrical integrated emitters using CFD analysis method. The experimental data and CFD analysis results obtained by using different turbulence models and wall functions were compared, and it was tried to define the CFD simulation method and wall function which was in harmonious with the experimental data.

\section{Materials and Methods}

\subsection{Experimental studies}

In the study, two different drip irrigation laterals (A and B type) with cylindrical type drip emitters were used. The general properties of the drip irrigation laterals are given in Figure 1 and Table 1. Inner diameter of the pipe was determined by using volumetric method (Bagerello et al 1997), and a digital caliper (accuracy of $\pm 0.01 \mathrm{~mm}$ ) was used in order to measure other dimensions of the drip emitters (Bagarello et al 1997).

A schematic diagram of the test apparatus is illustrated in Figure 2. The total friction losses were measured with piezometric tubes at various flow rates in $6 \mathrm{~m}$ section in the middle of $10 \mathrm{~m}$ length laterals. The total discharge at the end of the lateral was measured by using volumetric method. For this aim drip emitter outlets were sealed, and discharge was regulated by valves. Water temperature was measured between 18 and $22{ }^{\circ} \mathrm{C}$ during the experiments. The flow velocities in lateral were calculated by measured flow rates. The relationship between the flow velocities and the total friction losses in laterals was revealed. The properties of the drip emitter and pipe flow characteristics are given in Table 2.

\subsection{CFD analysis studies}

The total friction losses of A and B type drip irrigation laterals at different inlet velocities of

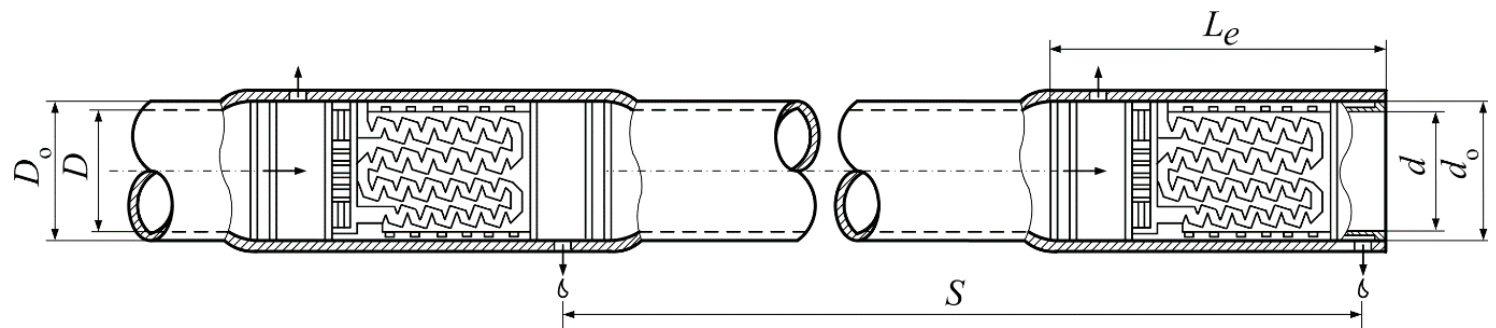

Figure 1- General properties of the drip irrigation laterals

Table 1- General dimensions of drip irrigation pipes and drip emitters

\begin{tabular}{|c|c|c|c|c|c|c|}
\hline \multirow{3}{*}{$\begin{array}{l}\text { Type of drip } \\
\text { irrigation pipe }\end{array}$} & \multicolumn{2}{|c|}{ Pipe } & \multicolumn{3}{|c|}{ Drip emitter } & \multirow{3}{*}{$\begin{array}{c}\text { Drip emitter } \\
\text { spacing } \\
S(m)\end{array}$} \\
\hline & $\begin{array}{c}\text { Outer } \\
\text { diameter }\end{array}$ & $\begin{array}{c}\text { Inner } \\
\text { diameter }\end{array}$ & $\begin{array}{c}\text { Outer } \\
\text { diameter }\end{array}$ & $\begin{array}{c}\text { Inner } \\
\text { diameter }\end{array}$ & Length & \\
\hline & $D_{o}(\mathrm{~mm})$ & $D(\mathrm{~mm})$ & $d_{o}(m m)$ & $d(\mathrm{~mm})$ & $L_{e}(\mathrm{~mm})$ & \\
\hline A & 15.57 & 13.63 & 15.92 & 11.58 & 39.78 & \multirow{2}{*}{$0.33,0.50,0.75$} \\
\hline B & 15.67 & 13.59 & 15.65 & 11.62 & 31.58 & \\
\hline
\end{tabular}


Table 2- Properties of the drip emitter and pipe flow characteristics

\begin{tabular}{|c|c|c|c|c|c|c|}
\hline \multirow{3}{*}{$\begin{array}{c}\text { Type of } \\
\text { drip emitter }\end{array}$} & \multicolumn{3}{|c|}{ Properties of drip emitter } & \multicolumn{3}{|c|}{ Pipe flow characteristics ${ }^{* *}$} \\
\hline & \multirow{2}{*}{$\begin{array}{c}\text { Drip emitter } \\
\text { flow rate* } \\
q\left(L h^{-1}\right)\end{array}$} & \multirow[t]{2}{*}{$k$} & \multirow[t]{2}{*}{$x$} & $\begin{array}{c}\text { Range of measured } \\
\text { flow rate }\end{array}$ & $\begin{array}{c}\text { Range of Reynolds } \\
\text { number }\end{array}$ & \multirow{2}{*}{$\begin{array}{c}\text { Number } \\
\text { of exp. }\end{array}$} \\
\hline & & & & $Q\left(L h^{-1}\right)$ & $R_{e}$ & \\
\hline A & 4.22 & 1.388 & 0.483 & $236.4-873.4$ & $6079-22457$ & 42 \\
\hline B & 3.04 & 0.868 & 0.545 & $183.5-855.5$ & $4728-22050$ & 46 \\
\hline
\end{tabular}

*, average drip emitter pressure: $10 \mathrm{~m}$; ${ }^{* *}$, the pipe flow characteristics obtained during friction losses measurements for all drip emitter spacing given in Table 1

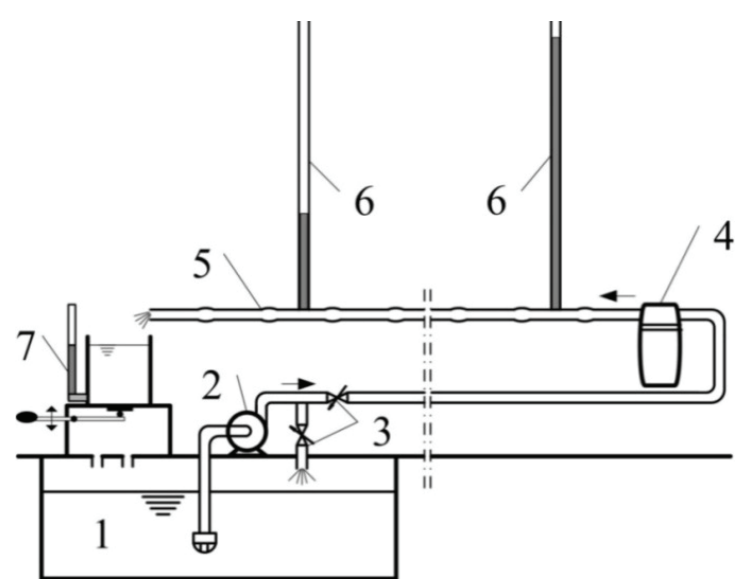

Figure 2- Experimental setup (1, reservoir; 2, pump; 3, valves; 4, disc filter; 5, experimental drip lateral; 6 , piezometric tubes; 7 , flow rate measurement unit)

water were calculated by using CFD software ANSYS Fluent 16.2 (ANSYS, Inc. Products USA Release 16.2).

\subsubsection{Geometrical model and mesh generation}

The geometrical models were created for $6 \mathrm{~m}$ length of A and B drip irrigation laterals for different drip emitter spacing $(0.33,0.50$ and $0.75 \mathrm{~m})$ by using ANSYS Design Modeller software. After created geometrical models, the mesh structures were formed by using ANSYS Meshing software (Figure $3)$. The number of nodes and elements in this mesh structures had more than $1.3 \times 10^{5}$ and $6.1 \times 10^{5}$, respectively. Elements are used to describe the area to be modeled. Elements are formed by joining nodes. The meshing quality parameters that are minimum orthogonal quality, maximum skewness and maximum aspect ratio occurred at the values of 0.23-0.26, 0.80-0.90 and 9.09-10.05, respectively.

\subsubsection{Mathematical model}

The flow can be described by the mass and momentum conservation equations. In the Newtonian, incompressible and steady-state flow condition, density of fluid is the constant, and the
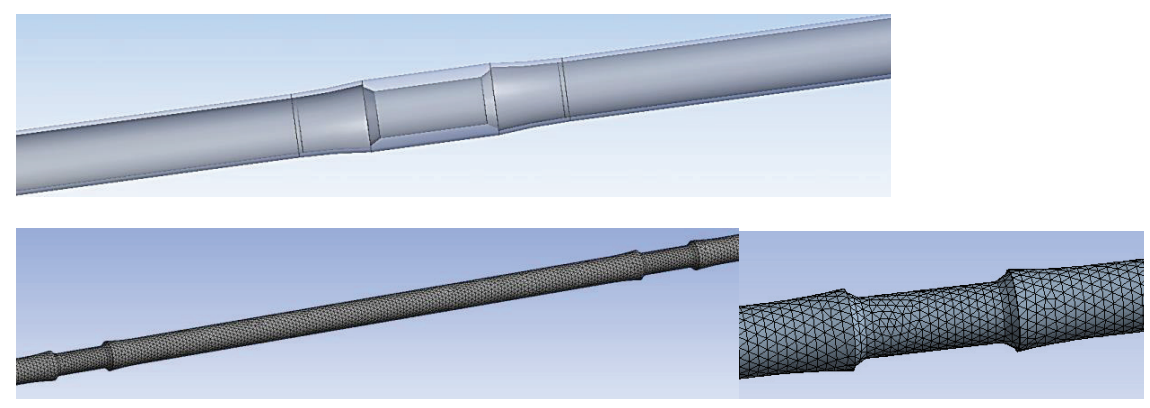

Figure 3- General view of the geometrical model and mesh structure 
conservation of mass, or continuity equation is defined as:

$\nabla \cdot \mathrm{V}=0$

Similarly, an incompressible Newtonian fluid with constant viscosity, in vector notation of the Navier-Stokes Equations is defined as:

$\rho\left(\frac{\partial \mathrm{v}}{\partial t}+(\mathrm{v} \cdot \nabla) \mathrm{v}\right)=-\nabla p+\rho \mathrm{g}+\mu \nabla^{2} \mathrm{v}$

In Equations; $\nabla$ is the vector operator $(\nabla=\partial / \partial x+\partial / \partial y+\partial / \partial z) ; \quad \mathrm{V}$, mean velocity vector $\left(\mathrm{m} \mathrm{s}^{-1}\right) ; \rho$, density of fluid $\left(\mathrm{kg} \mathrm{m}^{-3}\right) ; p$, static pressure $(\mathrm{Pa}) ; \mathrm{g}$, acceleration of gravity vector $(\mathrm{m}$ $\mathrm{s}^{-2}$ ); $\mu$, viscosity of fluid (Pa s) (White 2001; ANSYS 2016).

For the numerical analysis of Navier-Stokes Equations in turbulence flow, the approach is called as Reynolds Averaged Navier Stokes (RANS) Equations for the variation of fluctuating velocity, pressure and other scalar quantities considering take the time-average. Various turbulence models are used in the RANS approach to analyze the Reynolds stress tensor term $\left(-\rho \overline{u_{i}^{\prime} u_{j}^{\prime}}\right)$ appropriately, taking into account the effects of turbulence.

Several researchers have reported that the commonly used turbulence models are $k-\varepsilon$ turbulence model, $k-\omega$ turbulence model and Reynolds Stress Model (RSM) for vortex flow in drip irrigation laterals. The studies revealed that the turbulence models of $k-\varepsilon$ and $k$ - $\omega$ have given the similar results (Provenzano et al 2005b; Palau-Salvador et al 2006; Provenzano et al 2007; Vijiapurapu \& Cui 2010).

In CFD analysis, standard $k-\varepsilon$, RNG $k-\varepsilon$, realizable $k-\varepsilon$ turbulence models and Reynolds Stress Model (RSM) with Linear Pressure-Strain (LPS) were used for the friction loss calculations. For all turbulence models; standard wall function, non-equilibrium wall function and enhanced wall treatment were chosen as the Near-Wall Treatment.

\subsubsection{Boundary conditions and solution methods}

In ANSYS Fluent analysis; the fluid was chosen as water, it was assumed to be steady, incompressible, viscous, and non-gravity effect. The boundary conditions were selected as velocity-inlet and pressure-outlet of the drip irrigation lateral. All inlet flow velocity and outlet pressure values measured at various flow rates in the experiments were defined as the multiple parameters in CFD analysis. Hydraulic diameter values were taken into account. Surface roughness height of the internal pipe wall was accepted as $0.005 \mathrm{~mm}$ for PE pipes (White 2001). SIMPLEC (0) algorithms and Second Order Discretization Schemes were used in all solutions. In the study, a limit value of 250 iterations was accepted for the stability of the solution. The solution convergence accuracy was accepted to be $1 \times 10^{-5}$.

\subsection{Statistical analysis}

The mean absolute percentage error (MAPE) and the root mean square error (RMSE) were used to compare the differences between the experimental friction loss data and the predicted data using CFD models (Willmott \& Matsuura 2005; Willmott et al 2012). The lowest values of MAPE and RMSE represent the highest model prediction. MAPE and RMSE error parameters were calculated by the following equations.

$$
\begin{aligned}
& \text { MAPE }=\frac{100}{n} \sum_{i=1}^{n}\left|\frac{\Delta H_{K i, E x p}-\Delta H_{K i, C F D}}{\Delta H_{K i, E x p}}\right| \\
& \text { RMSE }=\left[\frac{1}{n} \sum_{i=1}^{n}\left(\Delta H_{K i, C F D}-\Delta H_{K i, E x p}\right)^{2}\right]^{1 / 2}
\end{aligned}
$$

Where; $\Delta H_{K i, E x p}$ is experimental and $\Delta H_{K i, C F D}$ is the simulation values, $n$ is the number of data.

\section{Results and Discussion}

In CFD analysis, standard $k-\varepsilon$, RNG $k-\varepsilon$, realizable $k-\varepsilon$ and RSM with LPS turbulence models, and standard wall function, non-equilibrium wall function and enhanced wall treatment were considered. 
The prediction of the total friction losses depending on the lateral type and drip emitter spacing was investigated for different near wall treatments. For this purpose, the CFD analysis results for standard wall function, non-equilibrium wall function and enhanced wall treatment by using standard $k-\varepsilon$ turbulence model were compared with the experimental results. The comparison results for A and B type drip irrigation laterals are given in Figure 4.

Based on the Figures 4, it was found that the total friction losses were predicted very close to
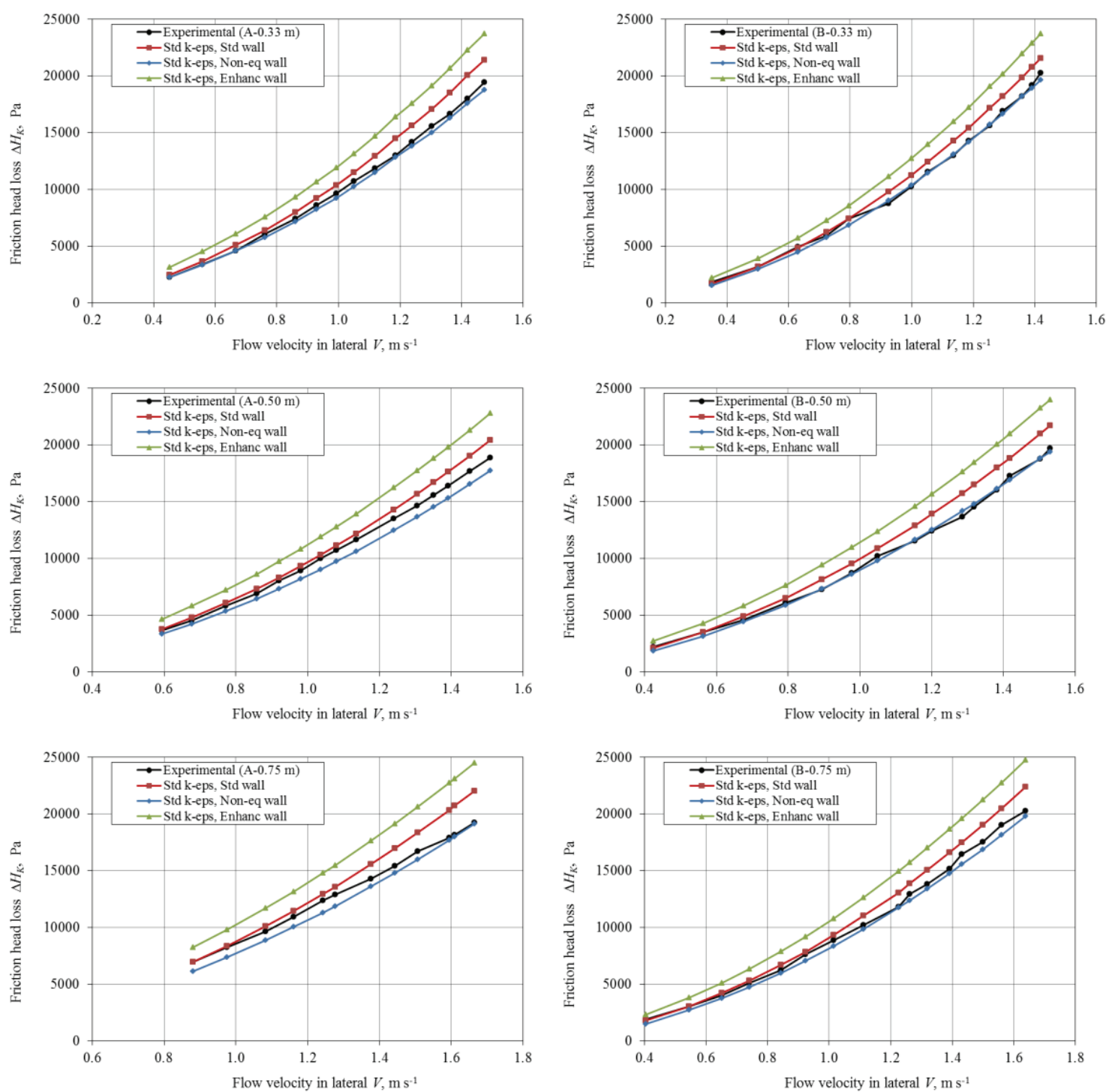

Figure 4- Comparison of experimental and standard $k-\varepsilon$ CFD analysis results of total friction losses for A and $B$ type drip irrigation lateral for different near wall treatments 
experimental data by using non-equilibrium wall function approach in CFD analysis conducted in different near wall treatments of standard $k-\varepsilon$ turbulence model. Using standard $k-\varepsilon$ turbulence model with standard wall function approach the experimental data were predicted nearly similar at lower flow velocity. However, it was found that the prediction was negatively affected based on the increasing of velocity. The worst prediction was occurred using enhanced wall treatment.

The mean absolute percentage error (MAPE) and the root mean square error (RMSE) were calculated to compare for the performances of CFD models (Table 3).

As seen in Table 3, among those CFD simulation models, the Reynolds Stress Model (RSM) with Linear Pressure-Strain turbulence model using standard wall function had the minimum MAPE and RMSE values of 2.96 and $369 \mathrm{~Pa}$, respectively. As seen in the table, the MAPE values in three turbulence models (realizable $k-\varepsilon$ and RNG $k-\varepsilon$ with standard wall function and standard $k-\varepsilon$ with non-equilibrium wall function) were found approximately 5\% while the RMSE values were found as 855,738 and 550 $\mathrm{Pa}$, respectively. Within these three turbulence models, the next closest prediction model was standard $k-\varepsilon$ with non-equilibrium wall function turbulence model with the lowest value of $550 \mathrm{~Pa}$ of RMSE.

In addition to the error parameters, to show the harmony between the experimental and predicted friction loss values for four CFD turbulence models having lowest MAPE values are given Figure 5.

As shown in the Figure, realizable $k-\varepsilon$ and RNG $k-\varepsilon$ with standard wall function seem to be very similar to each other. These results also overlap with the error parameters results (Table 3 ). On the other hand, a good agreement between experimental results and the predicted values by CFD simulation models exist for standard $k-\varepsilon$ with non-equilibrium wall function and especially RSM-LinPressStrain model with standard wall function (Figure 5).

Prediction values obtained with all turbulence models under the same near wall treatments were compared to the experimental total friction losses. Comparisons are given in Figures 6 and 7 for $\mathrm{A}$ and $\mathrm{B}$ drip irrigation laterals, respectively. The enhanced wall treatment was not considered in the comparison since it has the highest deviation (Table 3 and Figure 4).

It is clear from Figures 6 and 7 that different turbulence models may differently predict the experimental data based on the standard and nonequilibrium wall functions.

Figures 6 and 7 show that the highest predictions were obtained using RSM-LPS with standard wall function and standard $k-\varepsilon$ with non-equilibrium wall function turbulence models for A and B type drip irrigation laterals in different drip emitter spacings.

These results were in harmonious with the other studies using the similar models (Provenzano et al 2005b; Palau-Salvador et al 2006; Provenzano et

Table 3- The MAPE and RMSE results for all simulation models

\begin{tabular}{lcccccc}
\hline & \multicolumn{3}{c}{ Mean absolute percentage error } & \multicolumn{3}{c}{$\begin{array}{c}\text { Root mean square error } \\
\text { MAPE (\%) }\end{array}$} \\
\cline { 2 - 7 } CFD models & $\begin{array}{c}\text { Standard } \\
\text { wall } \\
\text { function }\end{array}$ & $\begin{array}{c}\text { Non-equilibrium } \\
\text { wall function }\end{array}$ & $\begin{array}{c}\text { Enhanced } \\
\text { wall } \\
\text { treatment }\end{array}$ & $\begin{array}{c}\text { Standard } \\
\text { wall } \\
\text { function }\end{array}$ & $\begin{array}{c}\text { Non-equilibrium } \\
\text { wall function }\end{array}$ & $\begin{array}{c}\text { Enhanced } \\
\text { wall } \\
\text { treatment }\end{array}$ \\
\hline Standard $k-\varepsilon$ & 7.51 & 4.87 & 23.29 & 1184 & 550 & 2856 \\
Realizable $k-\varepsilon$ & 5.15 & 7.60 & 22.15 & 855 & 858 & 2673 \\
RNG $k-\varepsilon$ & 4.61 & 8.65 & 21.29 & 738 & 917 & 2559 \\
RSM-LinPressStrain & 2.96 & 11.85 & 20.35 & 369 & 1276 & 2453 \\
\hline
\end{tabular}



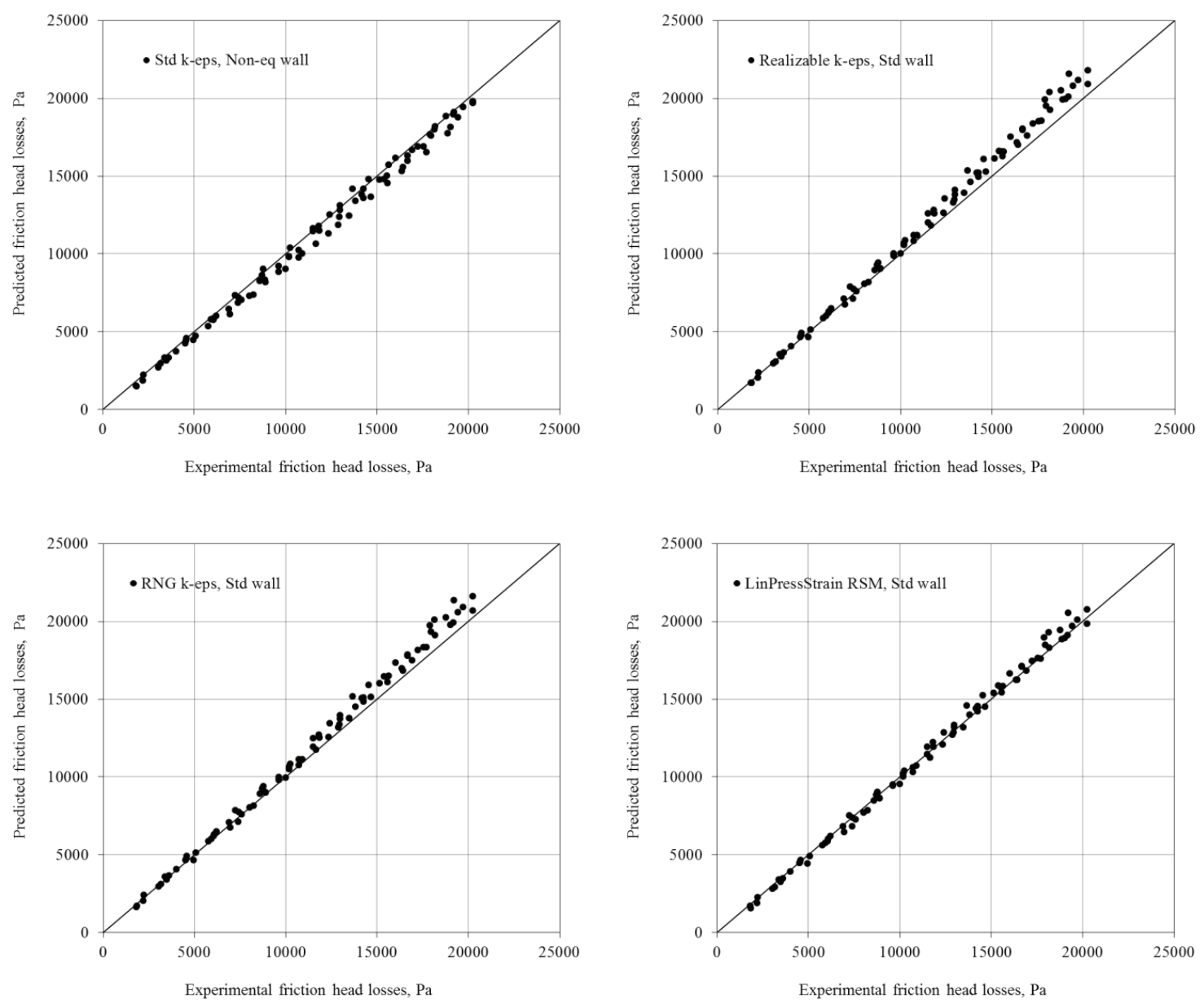

Figure 5- Comparison of the experimental and predicted friction head losses for considered closest prediction turbulence models

al 2007). Vijiapurapu \& Cui (2010) used $k-\varepsilon, k-\omega$, RSM and LES (Large Eddy Simulation) turbulence models at constant Reynolds number $(R e=100000)$ to determine the analyzing time using only straight lateral. They found that the head losses results, and $k-\varepsilon$ and RSM turbulence models results were similar in their study.

The comparison of experimental and CFD analysis results that provide the highest prediction for turbulence models with near wall treatments for A and $B$ type drip irrigation laterals in different drip emitter spacing are given in Table 4. Total friction loses were measured and calculated by CFD at 0.5 , 1.0 and $1.5 \mathrm{~m} \mathrm{~s}^{-1}$ water flow velocity in lateral, and deviation between measured and calculated total friction losses for all data were determined as a percentage.

As seen from Table 4, the average percentage differences were found between the $-7.66 \%$ and $12.43 \%$ for considered flow velocity. Also, the average percentage differences were found between the $-3.42 \%$ and $4.54 \%$ for all measured data. 

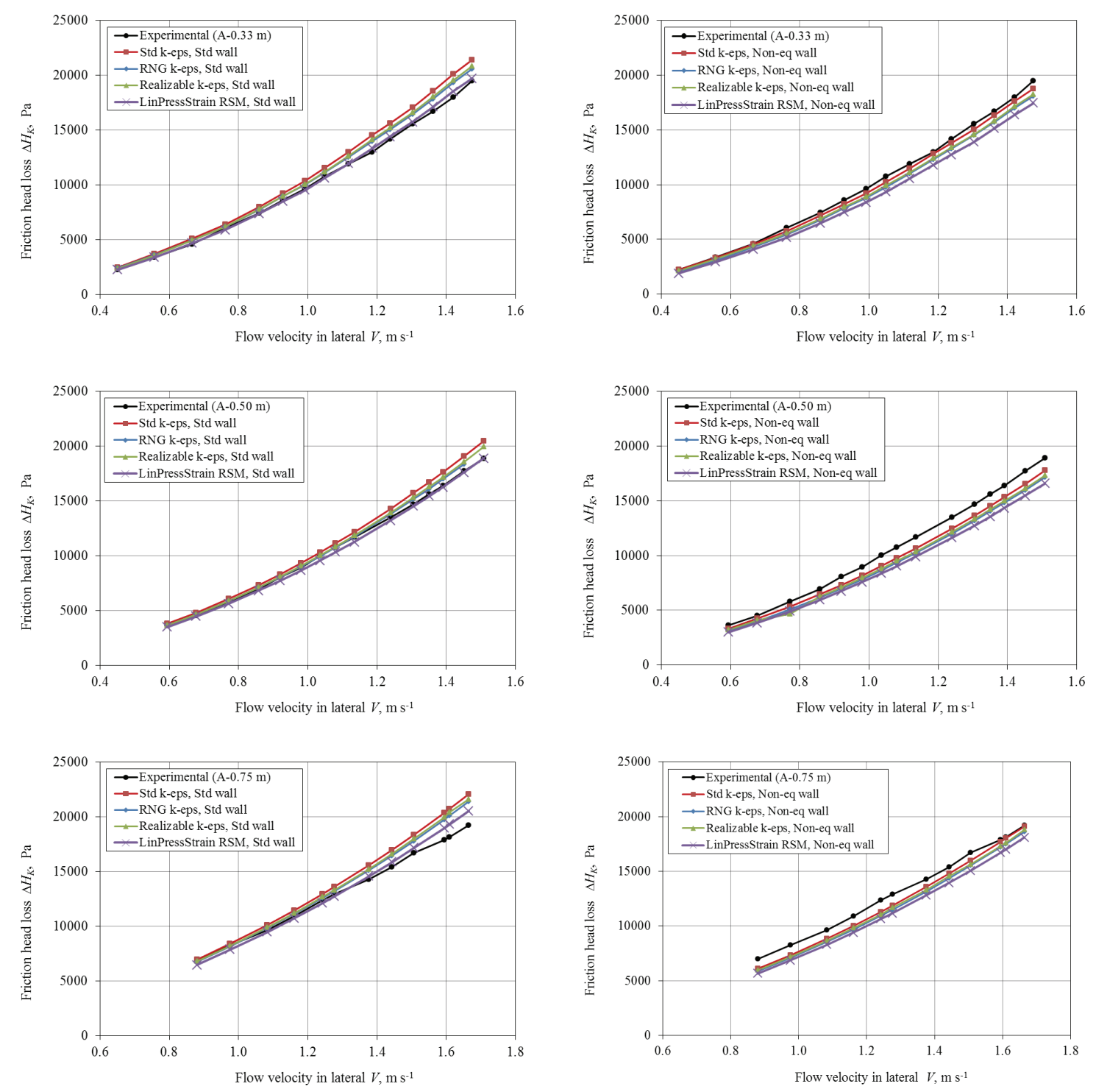

Figure 6- Comparison of experimental and CFD analysis results ( $k-\varepsilon$ and RSM turbulence models with standard and non-equilibrium wall functions) of total friction losses for A type drip irrigation lateral

These results had a similarity with Provenzano et al (2005b) and Provenzano et al (2007). They calculated the deviations between $-4.7 \%$ and $10.9 \%$ using CFD analysis method.

The lowest average percentage difference of all data was found in RSM with LPS turbulence model using standard wall function with $0.92 \%$. Similarly, the same model had the lowest error parameters as MAPE of $2.96 \%$ and RMSE of $369 \mathrm{~Pa}$ (Table 3). According to these results, it could be said that the RSM with LPS turbulence model using standard wall function was the closest prediction model for the total friction losses. 

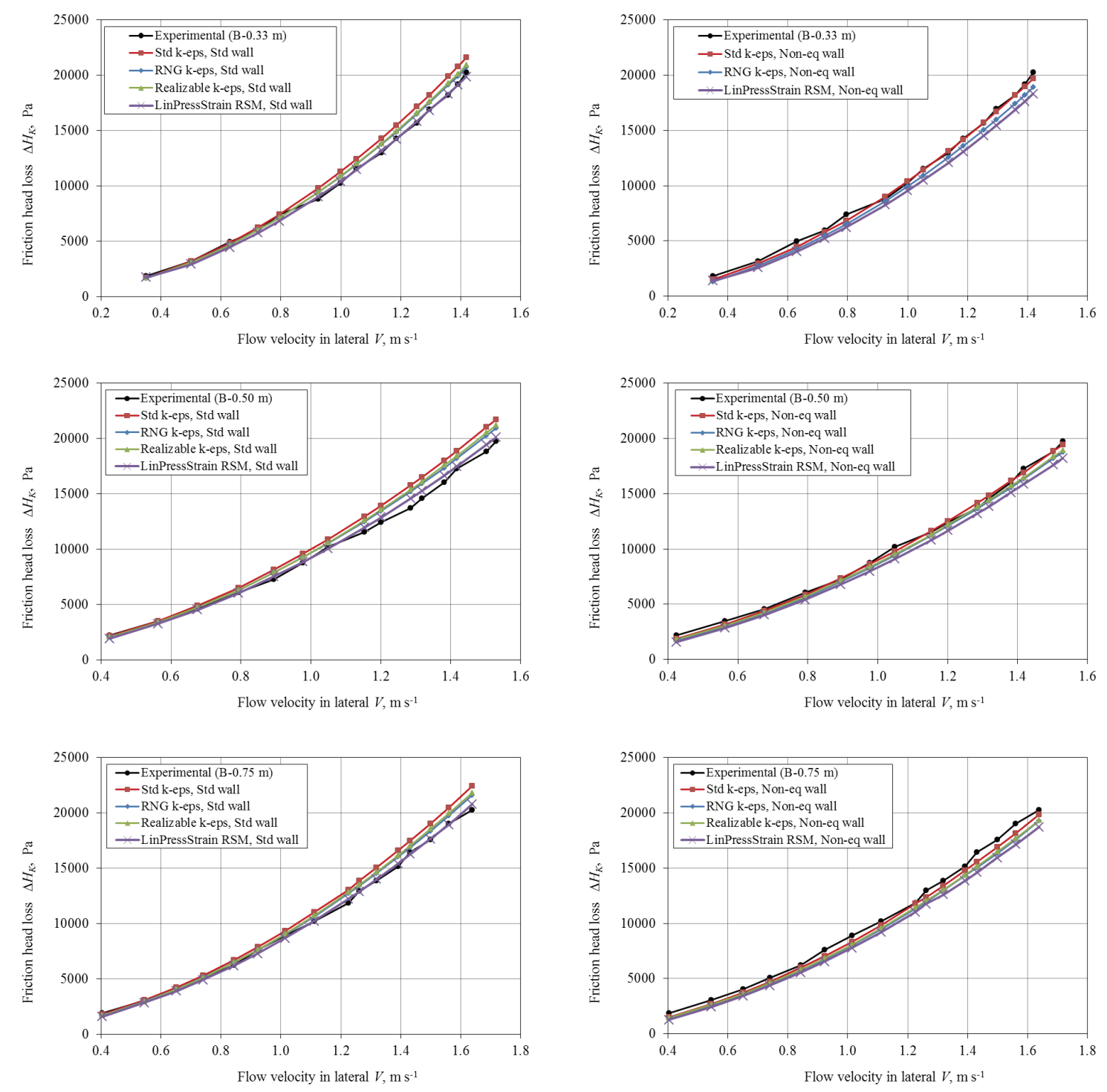

Figure 7- Comparison of experimental and CFD analysis results ( $k-\varepsilon$ and RSM turbulence models with standard and non-equilibrium wall functions) of total friction losses for $B$ type drip irrigation lateral

An example of the pressure distribution along the lateral line due to friction loss according to CFD analysis was shown in Figure 8. The example includes the CFD analysis results for RSM-LPS turbulence model with standard wall function model applied for B type emitter ( $0.33 \mathrm{~m}$ emitter spacing and $1 \mathrm{~m} \mathrm{~s}^{-1}$ inlet velocity).
As can be seen in Figure 8, a considerable amount of friction loss was occurred in the lateral section that was between the sequence emitter spacings. Except this friction loss, the friction losses due to pressure changes resulting from sudden contraction and expansion based on the emitter are also clearly seen 


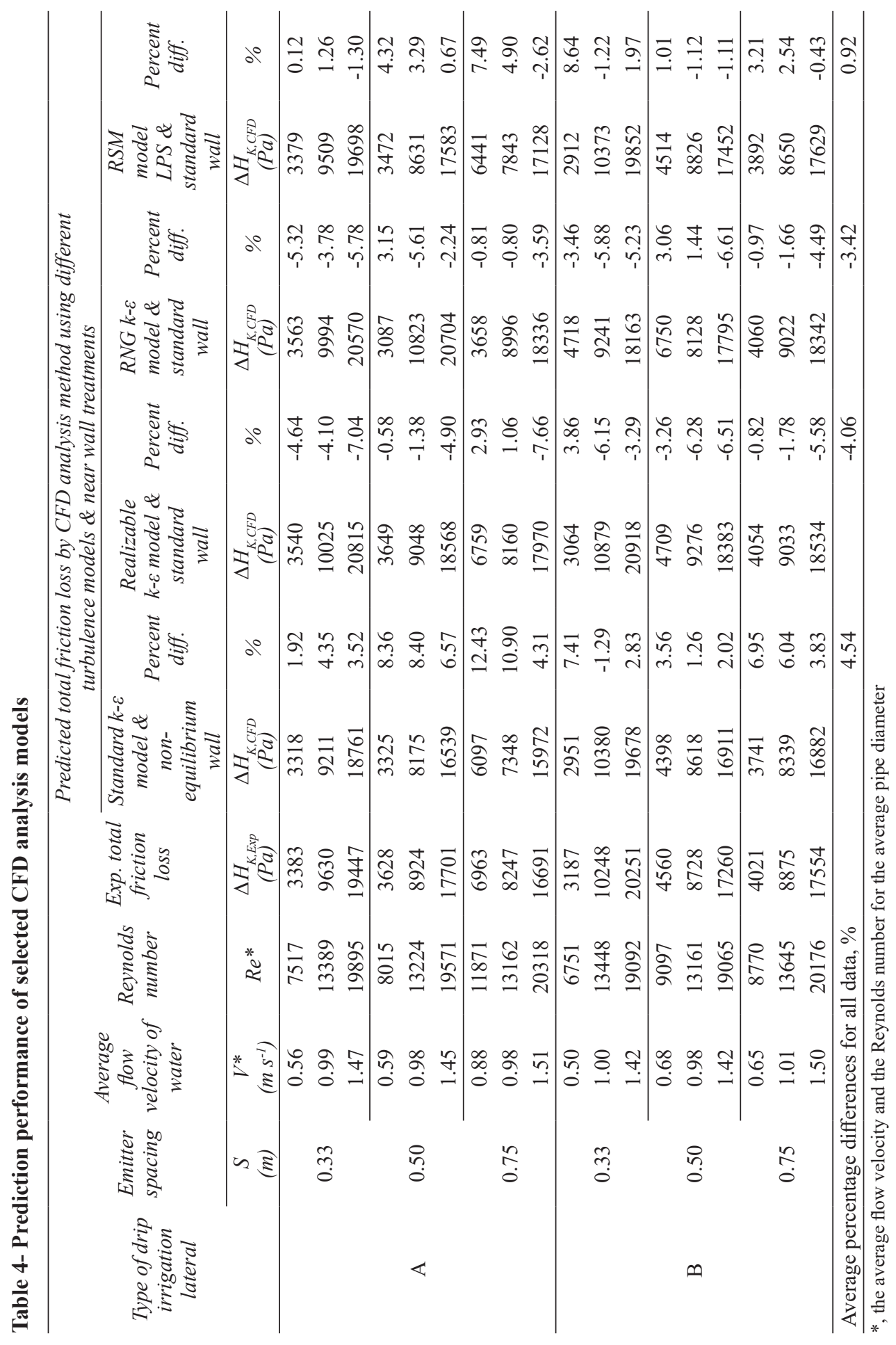



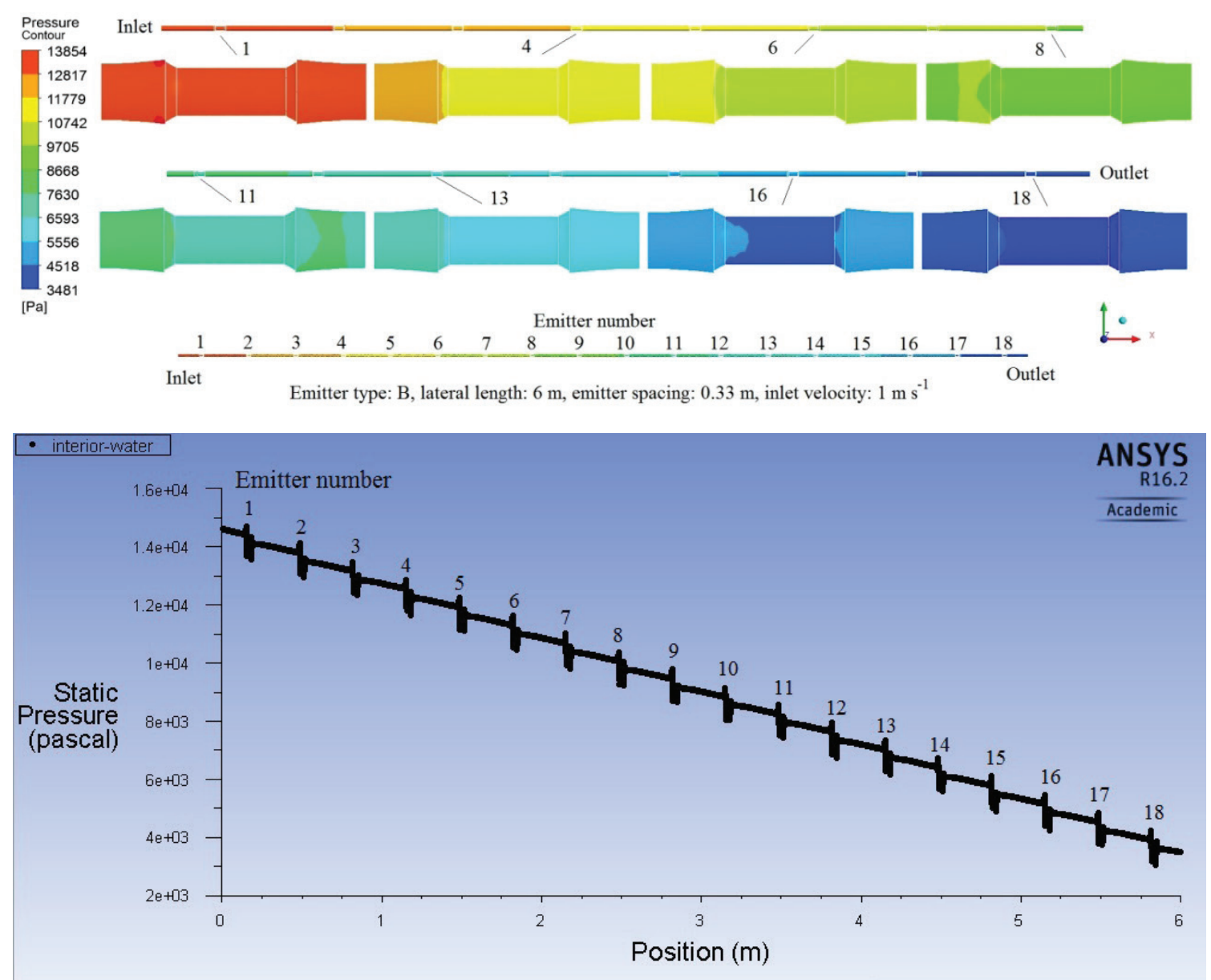

ANSYS Fluent Release 16.2 (3d, dp, pbns, RSM)

Figure 8- Pressure distribution along the lateral line with CFD analysis for RSM-LPS turbulence model with standard wall function

in Figure 8. Many researchers have expressed that the local friction losses need to be in consideration in the studies (Bagarello et al 1997; Juana et al 2002; Provenzano \& Pumo 2004). The analysis results clearly showed the same necessity, too.

\section{Conclusions}

It can be concluded that the considered turbulence models in CFD analysis can be used in prediction of the total friction losses of drip irrigation laterals with high accuracy if the near wall treatments were considered in the analyzing.

The closest prediction of total friction losses to experimental results was obtained by RSM with LPS turbulence model using standard wall function $(\mathrm{MAPE}=2.96 \%, \mathrm{RMSE}=369 \mathrm{~Pa})$. The next closest prediction was achieved using standard $k-\varepsilon$ turbulence model with non-equilibrium wall function with the lowest RMSE value of $550 \mathrm{~Pa}$. It is thought that the study results would be beneficial 
for researchers and manufacturers working on this subject.

\section{References}

ANSYS (2016). Fluent Theory Guide, Release 17.2, ANSYS, Inc.

Anyoji H \& Wu I P (1987). Statistical approach for drip lateral design. Transactions of the ASAE 30(1): 187192

Bagarello V, Ferro V, Provenzano G \& Pumo D (1997). Evaluating pressure losses in drip-irrigation lines. Journal of Irrigation and Drainage Engineering ASCE 123(1): 1-7

Demir V, Yurdem H \& Degirmencioglu A (2007). Development of prediction models for friction losses in drip irrigation laterals equipped with integrated inline and on-line emitters using dimensional analysis. Biosystems Engineering 96(4): 617-631

Juana L, Rodriguez-Sinobas L \& Losada A (2002). Determining minor head losses in drip irrigation laterals. II: Experimental study and validation. Journal of Irrigation and Drainage Engineering ASCE 128(6): 385-396

Kang Y \& Nishiyama S (1996). Analysis of microirrigation systems using a lateral discharge equation. Transactions of the ASAE 39(3): 921-929

Palau-Salvador G, Sanchis L H, González-Altozano P \& Arviza-Valverde J (2006). Real local losses estimation for on-line emitters using empirical and numerical procedures. Journal of Irrigation and Drainage Engineering ASCE 132(6): 522-530

Provenzano G \& Pumo D (2004). Experimental analysis of local pressure losses for microirrigation laterals. Journal of Irrigation and Drainage Engineering ASCE 130(4): 318-324

Provenzano G, Pumo D \& Dio P Di (2005a). Simplified procedure to evaluate head losses in drip irrigation laterals. Journal of Irrigation and Drainage Engineering ASCE 131(6): 525-532

Provenzano G, Pumo D, Di Dio P, Arviza-Valverde J \& Palau-Salvador G (2005b). Assessing a Computational Fluid Dynamics technique (CFD) to evaluate pressure losses in co-extruded drip laterals. In: Proceedings of the ASAE International Meeting, 17-20 July, Tampa Florida, Paper Number: 052212, pp. 1-12

Provenzano G, Di Dio P \& Palau-Salvador G (2007). New computational fluid dynamic procedure to estimate friction and local losses in coextruded drip laterals. Journal of Irrigation and Drainage Engineering ASCE 133(6): 520-527

Provenzano G, Di Dio P M \& Leone R (2014). Assessing a local losses evaluation procedure for low-pressure lay-flat drip laterals. Journal of Irrigation and Drainage Engineering ASCE 140(6): 04014017-1, 04014017-7

Vijiapurapu S \& Cui J (2010). Performance of turbulence models for flows through rough pipes. Applied Mathematical Modelling 34(6): 1458-1466

Von Bernuth R D \& Solomon K H (1986). Design principles-emitter construction (Chapter 2). In: $\mathrm{G} \mathrm{S}$ Nakayama \& D A Bucks (Eds.), Trickle Irrigation for Crop Production, Elsevier Science Publishers, The Netherlands, pp. 27-52

Wang W, Wang F \& Zhao F (2006). Simulation of unsteady flow in labyrinth emitter of drip irrigation system. Computers in Agriculture and Natural Resources, $4^{\text {th }}$ World Congress Conference, 24-26 July, Orlando, Florida, ASABE Publication Number 701P0606, pp. 630-635

Wei Q, Shi Y, Dong W, Lu G \& Huang S (2006). Study on hydraulic performance of drip emitters by computational fluid dynamics. Agricultural Water Management 84(1-2): 130-136

White F M (2001). Fluid Mechanics. $4^{\text {th }}$ Edition, McGraw Hill, New York

Willmott C J \& Matsuura K (2005). Advantages of the mean absolute error (MAE) over the root mean square error (RMSE) in assessing average model performance. Climate Research 30: 79-82

Willmott C J, Robeson S M \& Matsuura K (2012). A refined index of model performance. International Journal of Climatology 32: 2088-2094

Zhang J, Zhao W, Wei Z, Tang Y \& Lu B (2007). Numerical and experimental study on hydraulic performance of emitters with arc labyrinth channels. Computer and Electronics in Agriculture 56(2): 120-129 